\title{
Compression-Molded Products Based on Wet Ball-Milled Wood and Effect of Various Preparation Conditions
}

\begin{abstract}
Kentaro Abe
This study prepared compression-molded products from ball-milled wood by thermally plasticizing lignin without adhesives or resins. Wet ball milling for 120 min produced smooth, creamy slurries. The resultant products were hotpressed at $180^{\circ} \mathrm{C}$ and exhibited a plastic-like glossy surface and a high Young's modulus (7.9 GPa), which was attributed to an increased bonding area. However, hydrogen bond formation occurs more predominantly during wood molding than thermoplasticization of lignin, because a hydrophilic surface was formed on wood fragments after wet ball milling in water. In contrast, when wood powder was ball-milled in toluene, drying aggregation due to hydrogen bond formation hardly occurred probably because the hydrophobic regions were preferentially cleaved. In this case, the hot-pressed product at $180^{\circ} \mathrm{C}$ was formed mostly through the bonding owing to the thermoplasticization of lignin. These results suggest that the choice of the solvent for the mechanical disintegration of wood allows for control of the wood fragment surface and can affect the properties of the molded products.
\end{abstract}

Keywords: Binderless board; Ball milling; Thermoplasticization; Hydrophilic; Hydrophobic surface

Contact information: Research Institute for Sustainable Humanosphere, Kyoto University, Gokasyo, Uji, Kyoto, 611-0011, Japan; *Corresponding: abekentaro@ rish.kyoto-u.ac.jp

\section{INTRODUCTION}

Wood cell walls consist of stiff fillers, called cellulose microfibrils, embedded in matrix substances such as hydrophilic hemicelluloses and hydrophobic lignin. Fratzl et al. (2004) pointed out that these structural features of wood cell walls may determine the stiffness and toughness of wood composites. Therefore, wood cell walls are an ideal nanocomposite and can provide support to a large body of trees.

The thermoplasticity of lignin has facilitated the production of binderless boards using ligno-plant-based materials such as wood and kenaf without the use of additional adhesives or resins (Anglès et al. 1999; Widyorini et al. 2005; Bouajila et al. 2008; Tajuddin et al. 2016). From the hot-pressing process used to create the boards, it is known that lignin becomes thermoplastic at temperatures exceeding $180^{\circ} \mathrm{C}$ (Takahashi et al. 2010; Kurokochi and Sato 2020). To improve the mechanical properties of ligno-plant-based binderless boards, we previously prepared nanofragments from a chemi-thermomechanical pulp (CTMP) by mechanical disintegration using a grinder (Abe et al. 2009). The nanofragments consisted of cellulose microfibrils and were encased in hydrophobic lignin. The compression-molded product from the CTMP fragments was produced by hot-pressing (at $180{ }^{\circ} \mathrm{C}$ ), and it exhibited a high compactness and a high Young's modulus (7.9 GPa). The motivation for the development of CTMP products was to harness the structural features of wood cell walls for the production of stiff and tough nanocomposites.

This study applies the above concept to Hinoki wood powder, utilizing a ball mill in place of the grinder. A ball mill is often used as a pretreatment to disintegrate plant 
material. It provides a simple and cost-effective way to prepare cellulose nanofibers and nanocrystals (Piras et al. 2019). Ball milling with toluene, which is a non-polar solvent, is used as a pretreatment to extract lignin from milled wood (Bjorkman 1965; Ikeda et al. 2002).

Here, wet ball milling created disintegrated products that were subsequently molded by hot-pressing. The effects of the milling time and molding conditions on the mechanical properties of the products were examined. Furthermore, the effect of different solvents was investigated on the bonding arrangement in the molded products, by wet ball milling with either water or toluene. This study uses a zirconia ball mill, which is similar to a grinder, for nanodisintegration of plant sources (Abe et al. 2007; Abe 2019).

\section{EXPERIMENTAL}

\section{Materials and Disintegration}

Hinoki (Chamaecyparis obtusa Endl.) wood powder was used. This wood powder was mixed with water (or toluene) (w:v\%; 15:85) and disintegrated by planetary ball milling (Fritsch Pulverisette 6, Idar-Oberstein, Germany) at $400 \mathrm{rpm}$ using a zirconia pot and $20 \mathrm{~mm}$ balls. The pot was filled to one-third of its volume with the wood powder, water, and zirconia balls. The samples were milled for 60 or $120 \mathrm{~min}$ in cycles of $10 \mathrm{~min}$ milling followed by a 20 min pause. Finally, the obtained wood slurry was separated from the balls using a stainless steel mesh.

\section{Compression-molding}

The wood slurry before and after ball milling was filled into a rectangular mold (40 $\times 9 \times 1 \mathrm{~mm}$ ) and oven-dried at $120^{\circ} \mathrm{C}$. The oven-dried samples were kept in dry conditions at room temperature for 1 day. The moisture content of the dried samples was approximately $10 \%$. The dried samples were hot-pressed for 20 min at either 120 or $180{ }^{\circ} \mathrm{C}$ between two highly polished steel plates under a pressure of $200 \mathrm{MPa}$. The products were cooled under the same pressure until they reached room temperature. The molded products were about $7.5 \mathrm{~mm}$ in width and about $200 \mu \mathrm{m}$ in thickness. The slurry milled with toluene was air-dried in a draft chamber and mixed with water to a concentration of $15 \mathrm{wt} \%$. The molded products were prepared as described above.

\section{Characterization}

For microscopic observations, the slurry was diluted with water (or toluene) after ball milling and the cast films were prepared on silicon substrate at $120^{\circ} \mathrm{C}$. The films were coated with platinum ( $2 \mathrm{~nm}$ thickness) using an ion sputter coater and observed by field emission scanning electron microscopy (FE-SEM, JSM-6700 F, JEOL, Tokyo, Japan) at the accelerating voltage of $1.5 \mathrm{kV}$ with the working distance of $10 \mathrm{~mm}$

The tensile properties of the molded products were measured using a universal material testing machine (model 3365; Instron Corp., Canton, MA, USA) with a crosshead speed of $1 \mathrm{~mm} / \mathrm{min}$ and a gauge length of $20 \mathrm{~mm}$. At least five specimens were tested for each sample and the mean tensile values were calculated. The density was calculated by measuring the average thickness of the samples at three points and the air-dried weight. The specific modulus was calculated by dividing the average Young's modulus by the density of the molded products. 


\section{RESULTS AND DISCUSSION}

In this study, wood samples were made up to $15 \mathrm{wt} \%$ with water and were disintegrated by planetary ball milling. Although the slurry had a rough texture after 60 min milling, a smooth, creamy, brown slurry was obtained after 120 min milling. The particle size of the original wood powder was approximately $200 \mu \mathrm{m}$ (Fig. 1(a)); after ball milling for $60 \mathrm{~min}$, it had decreased to a few micrometers (Fig. 1(b)). After 120 min of ball milling, the particle size could not be determined because of aggregation during the drying process. However, large fragments were rarely seen and smooth textures and surfaces were observed in the samples that were milled for 120 min (Fig. 1(c)), suggesting further disintegration upon extended ball milling.
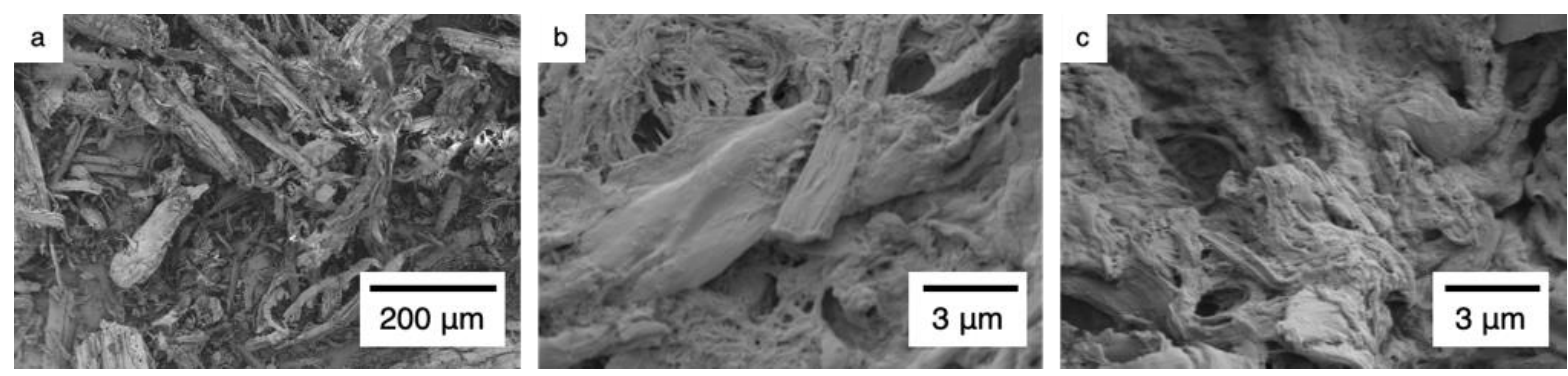

Fig. 1. FE-SEM images of (a) the original wood powder (at 100x magnification) and the samples in water, ball-milled for (b) $60 \mathrm{~min}$, and for (c) $120 \mathrm{~min}$ (each at 5,000× magnification).

The products prepared from the original powder ( 0 min milling time) were presumed to have many voids (Table 1) because the density of wood cell wall substance is generally 1.4 to $1.5 \mathrm{~g} / \mathrm{cm}^{3}$. The density, Young's modulus, tensile strength, and strain at break significantly increased after $60 \mathrm{~min}$ of milling. Further slight increases in the Young's modulus and tensile strength were observed after $120 \mathrm{~min}$ of milling (Table 1). These results indicate that ball milling in water produced fine fragments that filled the voids in the product, increased density, and enhanced mechanical properties.

Table 1. Effect of Milling Time in Water on Mechanical Properties of Molded Products Pressed at $180^{\circ} \mathrm{C}$

\begin{tabular}{|c|c|c|c|c|}
\hline Milling time & $\begin{array}{c}\text { Density } \\
\left(\mathrm{g} / \mathrm{cm}^{3}\right)\end{array}$ & $\begin{array}{c}\text { Young's Modulus } \\
(\mathrm{GPa})\end{array}$ & $\begin{array}{c}\text { Tensile Strength } \\
(\mathrm{MPa})\end{array}$ & $\begin{array}{c}\text { Strain at Break } \\
(\%)\end{array}$ \\
\hline $0 \mathrm{~min}$ & $1.28(0.04)$ & $5.1(1.2)$ & $12.6(4.6)$ & $0.33(0.04)$ \\
\hline $60 \mathrm{~min}$ & $1.39(0.01)$ & $7.8(0.3)$ & $59.0(5.2)$ & $0.96(0.08)$ \\
\hline $120 \mathrm{~min}$ & $1.35(0.05$ & $7.9(0.5)$ & $63.1(13.1)$ & $0.93(0.20)$ \\
\hline
\end{tabular}

Note: Data are means (s.d.) of $n \geqq 5$.

The effect of the molding conditions on the mechanical properties of the products was investigated. In order to confirm the effect of hot-pressing at $180{ }^{\circ} \mathrm{C}$ on the formation of the molded products, the milled slurry was oven-dried at $120{ }^{\circ} \mathrm{C}$ and then hot-pressed at 120 or $180^{\circ} \mathrm{C}$ for comparison. The samples hardened significantly after oven-drying at 120 ${ }^{\circ} \mathrm{C}$ due to aggregation through hydrogen bonding during drying. As can be seen in Table 2, hot-pressing at $120^{\circ} \mathrm{C}$ significantly increased the density and the Young's modulus of this product. On the other hand, for the molded product pressed at $180{ }^{\circ} \mathrm{C}$, the Young's 
modulus increased slightly, and the density, tensile strength, and strain at break were similar compared to the products pressed at $120^{\circ} \mathrm{C}$. These results suggest that the lignin's thermoplasticity (occurs $>180^{\circ} \mathrm{C}$ ) may only slightly affect the mechanical properties of the products. Furthermore, hot-pressing at $180{ }^{\circ} \mathrm{C}$ certainly was effective because only this product displayed a smooth and plastic-like glossy surface. Such changes in the surface texture could not occur merely due to hydrogen bonding.

Table 2. Effect of Molding Condition on Mechanical Properties of Molded Products after 120 Min Milling in Water

\begin{tabular}{|l|c|c|c|c|}
\hline \multicolumn{1}{|c|}{ Condition } & $\begin{array}{c}\text { Density } \\
\left(\mathrm{g} / \mathrm{cm}^{3}\right)\end{array}$ & $\begin{array}{c}\text { Young's } \\
\text { Modulus }(\mathrm{GPa})\end{array}$ & $\begin{array}{c}\text { Tensile Strength } \\
(\mathrm{MPa})\end{array}$ & $\begin{array}{c}\text { Strain at Break } \\
(\%)\end{array}$ \\
\hline Dried at $120^{\circ} \mathrm{C}$ & $1.20(0.04)$ & $6.3(0.2)$ & $43.8(2.5)$ & $1.11(0.25)$ \\
\hline $\begin{array}{l}\text { Pressed at } 120 \\
{ }^{\circ} \mathrm{C}\end{array}$ & $1.39(0.02)$ & $7.3(0.1)$ & $66.2(7.7)$ & $1.13(0.19)$ \\
\hline $\begin{array}{l}\text { Pressed at } 180 \\
{ }^{\circ} \mathrm{C}\end{array}$ & $1.35(0.05$ & $7.9(0.5)$ & $63.1(13.1)$ & $0.93(0.20)$ \\
\hline
\end{tabular}

Note: Data are means (s.d.) of $n \geqq 5$.

These results indicate that mechanical disintegration by wet milling is effective for improving the mechanical properties of the binderless products. However, the problem persists that the molded products may be formed predominantly through aggregation during drying. To address this, the specific moduli of the molded products are compared and the bonding between the fragments in the molded products is examined. These are calculated based on the data in Tables 1 and 2. As shown in Fig. 2(a), the specific modulus was drastically improved after 60 and 120 min of milling. This suggests that the increase in the Young's modulus by ball milling (see Table 1) was caused not only by an increase in the density (decrease in the number of voids) of the sample, but also by an increase in the bonding area between the fine fragments. However, the specific moduli were similar for the products that were dried at $120{ }^{\circ} \mathrm{C}$ and hot-pressed at $120{ }^{\circ} \mathrm{C}$ (Fig. 2(b)). This suggest that both the products had similar bonding areas, due to hydrogen bonding, and that hot-pressing at $120{ }^{\circ} \mathrm{C}$ increased only the density (decreases the number of voids) of the sample. However, hot-pressing at $180{ }^{\circ} \mathrm{C}$ increased the specific modulus, see Fig. 2(b). This slight increase is likely as a result of the increase in bonding area provided by the onset of the lignin's thermoplasticity at $180^{\circ} \mathrm{C}$. 

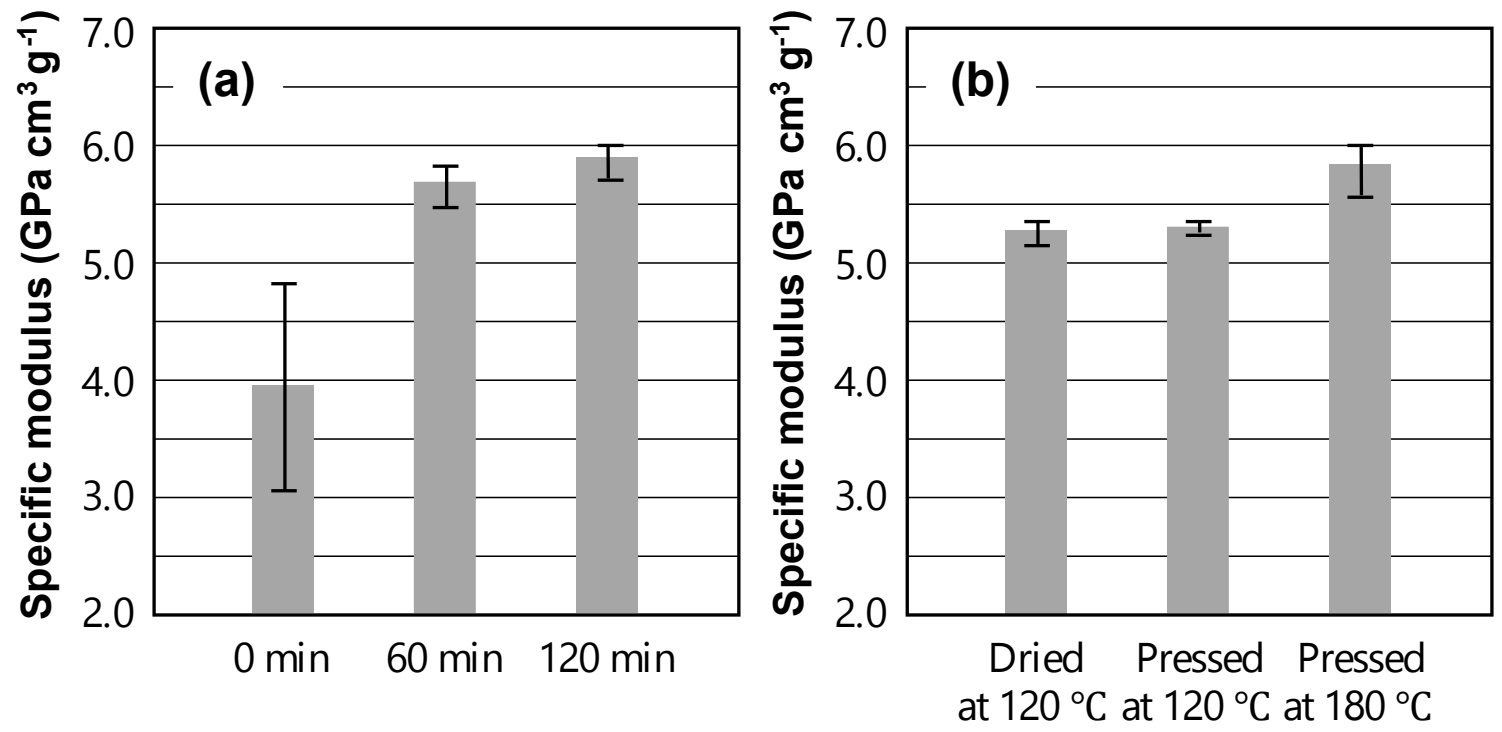

Fig. 2. Comparisons of the specific moduli of the molded products with different preparation conditions. (a) the effect of the milling time in water, (b) the effect of the molding conditions (120 min milling in water)

It is plausible that mechanical disintegration with water preferentially cleaves the hydrophilic regions in wood cell walls because water molecules can penetrate the hydrophilic regions and weaken hydrogen bonds. More hydrophilic surfaces are exposed in the wood fragments milled with water; thus, the molded products are formed mostly through hydrogen bonding during drying.

In order to test the above hypothesis, water was replaced with a hydrophobic solvent, toluene, during ball milling of the wood powder. After $120 \mathrm{~min}$ of ball milling in toluene, a smooth, creamy slurry was obtained similar to that when water was used. However, the slurry color was gray and the reason for this color change is unknown. Figure 3 shows that the wood powder milled with toluene produces fragments that are hundreds of nanometers in size.

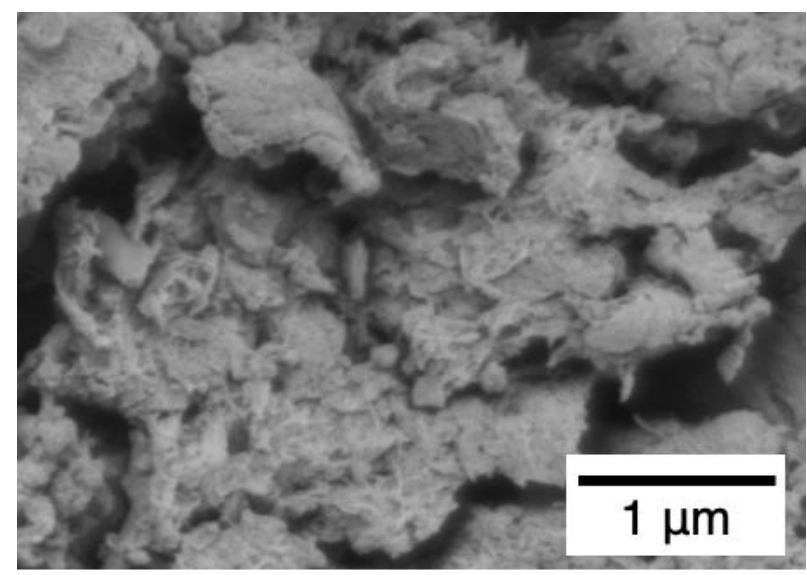

Fig. 3. FE-SEM image of the ball-milled sample in toluene, milled for 120 min (at 10,000x magnification). 
The products molded at $180{ }^{\circ} \mathrm{C}$, after milling in toluene, had similar densities to those that were milled in water, as shown in Table 3. Therefore, toluene is a viable alternative to water for ball milling. However, for the toluene-milled products, the Young's modulus was lower and the tensile strength and strain at break were significantly lower than those of water-milled products.

Table 3. Effect of Solvents on Mechanical Properties of Molded Products Pressed at $180^{\circ} \mathrm{C}$

\begin{tabular}{|r|c|c|c|c|}
\hline \multicolumn{1}{|c|}{ Solvents } & $\begin{array}{c}\text { Density } \\
\left(\mathrm{g} / \mathrm{cm}^{3}\right)\end{array}$ & $\begin{array}{c}\text { Young's } \\
\text { Modulus }(\mathrm{GPa})\end{array}$ & $\begin{array}{c}\text { Tensile Strength } \\
(\mathrm{MPa})\end{array}$ & $\begin{array}{c}\text { Strain at Break } \\
(\%)\end{array}$ \\
\hline Water & $1.35(0.05$ & $7.9(0.5)$ & $63.1(13.1)$ & $0.93(0.20)$ \\
\hline Toluene & $1.37(0.04)$ & $6.4(0.1)$ & $22.3(9.1)$ & $0.42(0.13)$ \\
\hline
\end{tabular}

Note: Data are means (s.d.) of $n \geqq 5$.

Figure 4 compares the specific moduli of the molded products pressed at 120 or $180{ }^{\circ} \mathrm{C}$ and subjected to either water or toluene milling. Hereafter, these molded products are referred to as W120, W180, T120, and T180 (W denotes water milling, T denotes toluene milling, and the number represents the pressing temperature). Although W120 shows a high specific modulus, interestingly, T120 was too brittle to be subjected to testing (Fig. 4(a): NA). Nonetheless, T180 becomes very stiff, with Young's and specific moduli values slightly lower than those of W180. Based on these results, Fig. 4(b) illustrates the bonding system in the molded products. Considering that the slurry milled in toluene was air-dried, mixed with water, and oven-dried at $120^{\circ} \mathrm{C}$, these conditions were favorable for hydrogen bonding. In contrast, the fact that T120 was very brittle suggests that the generation of a hydrophilic surface and the subsequent formation of hydrogen bonds were suppressed. The amount of hydrogen bonding in T120 is unknown but it should be very low. In Fig. 4(b), it was arbitrarily determined. Furthermore, a temperature of $120{ }^{\circ} \mathrm{C}$ was insufficient to achieve thermoplasticity. The high specific moduli values of T180 suggest that the wood fragments were well adhered due to the onset of the lignin's thermoplasticity at $180{ }^{\circ} \mathrm{C}$.
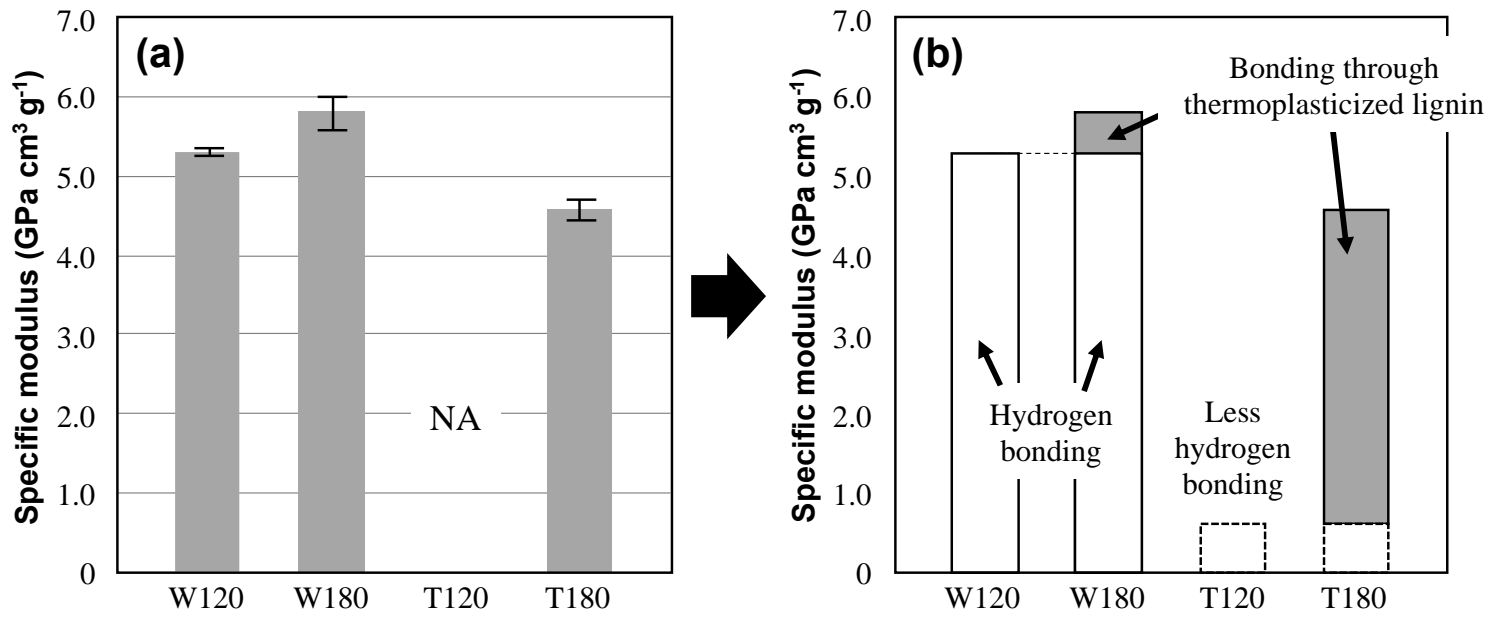

Fig. 4. (a) Comparison of the specific moduli of the products molded under different conditions and (b) the proportion of hydrogen bonding and thermoplasticized lignin bonding under different conditions. (NA - indicates that the specific modulus could not be measured for this sample as it was too brittle). 
As mentioned previously, the mechanical disintegration of the wood samples with water may increase the number of hydrophilic regions. In contrast, because toluene can penetrate the hydrophobic regions mainly consisting of lignin, in the wood cell walls, ball milling with toluene may expose more hydrophobic surfaces in the wood cell walls. Therefore, instead of hydrogen bond formation, the strength of the molded product from the sample milled using toluene originated from the onset of the thermoplasticity of lignin when pressed at $180{ }^{\circ} \mathrm{C}$. However, this does not mean that the molded product, derived from the sample milled using toluene (T180), does not absorb moisture because the amount of hydrophilic regions in the product does not change. The choice of solvent for mechanical disintegration affects the surface properties of wood fragments as well as the internal bonding in the molded products.

\section{CONCLUSIONS}

1. Hinoki wood powder was subjected to wet ball milling and the compression-molded products were produced without the use of resin or adhesives.

2. Ball milling for 120 min in water produced fine fragments, and the molded products exhibited the highest Young's modulus and tensile strength because of an increased bonding area.

3. The wet ball milling of wood with water selectively exposed the hydrophilic surfaces of the fragments. Therefore, the molded products prepared at $180{ }^{\circ} \mathrm{C}$ are formed primarily through hydrogen bonding rather than through the thermoplasticity of lignin.

4. The hydrogen bonding results in strong adhesion between fragments but the fragments may have a low water resistance.

5. Ball milling of wood with toluene exposes the hydrophobic surfaces of the fragments; thus, the molded products are primarily bound by the thermoplasticity of lignin.

6. It is still unknown whether wood fragments with hydrophobic surfaces display good affinity toward plastics, which could be useful for developing wood-plastic composites.

\section{REFERENCES CITED}

Abe, K., Iwamoto, S., and Yano, H. (2007). "Obtaining cellulose nanofibers with a uniform width of $15 \mathrm{~nm}$ from wood," Biomacromolecules 8(10), 3276-3278. DOI: $10.1021 / \mathrm{bm} 700624 \mathrm{p}$

Abe, K., Nakatsubo, F., and Yano, H. (2009). "High-strength nanocomposite based on fibrillated chemi-thermomechanical pulp," Composites Science and Technology 69 (14), 2434-2437. DOI: 10.1016/j.compscitech.2009.06.015

Abe, K. (2019). "Novel fabrication of high-modulus cellulose-based films by nanofibrillation under alkaline condition," Carbohydrate Polymers 205, 488-491. DOI: 10.1016/j.carbpol.2018.10.069

Anglès, M. N., Reguant, J., Montané, D., Ferrando, F., Farriol, X., and Salvaadó, J. (1999). "Binderless composites from pretreated residual softwood," J. Appl. Polym.

Sci. 73(12), 2485-2491. DOI: 10.1002/(SICI)1097-

4628(19990919)73:12<2485::AID-APP17>3.0.CO;2-G 
Bjorkman, A. (1956). "Studies on finely divided wood. Part I. Extraction of lignin with neutral solvents," Svensk Papperstidn 59, 477-485.

Bouajila, J., Limare, A., Joly, C., and Dole, P. (2008). "Lignin plasticization to improve binderless fiberboard mechanical properties," Polym. Eng. Sci. 45(6), 809-816. DOI: 10.1002/pen.20342

Fratzl, P., Burgert, I., Himadri, S., and Gupta, H. S. (2004). "On the role of interface polymers for the mechanics of natural polymeric composites," Phys. Chem. Chem. Phys. 6 (24), 5575-5579. DOI: 10.1039/B411986J

Ikeda, T., Holtman. K., Kadla, J. F., Chang, H. M., and Jameel, H. (2002). "Studies on the effect of ball milling on lignin structure using a modified DFRC method," J. Agric. Food. Chem. 50(1), 129-135. DOI: 10.1021/jf010870f

Kurokochi, Y., and Sato, M. (2020). "Steam treatment to enhance rice straw binderless board focusing hemicellulose and cellulose decomposition products," Journal of Wood Science 66(1), 7. DOI: 10.1186/s10086-020-1855-8

Piras, C. C., Fernández-Prieto, S., and De Borggraeve, W. M. (2019). "Ball milling: A green technology for the preparation and functionalisation of nanocellulose derivatives," Nanoscale Adv. 1(3), 937-947. DOI: 10.1039/C8NA00238J

Tajuddin, M., Ahmad, Z., and Ismail, H. (2016). "A review of natural fibers and processing operations for the production of binderless boards," BioResources 11(2), 5600-5617. DOI: 10.15376/biores.11.2. Tajuddin

Takahashi, I., Sugimoto, T., Takasu, Y., Yamasaki, M., Sasaki, Y., and Kikata, Y. (2010). "Preparation of thermoplastic molding from steamed Japanese beech flour," Holzforschung 64 (2), 229-234. DOI: 10.1515/hf.2010.035

Widyorini, R., Higashihara, T., Xu, J., Watanabe, T., and Kawai, S. (2005). "Self-bonding characteristics of binderless kenaf core composites," Journal of Wood Science 39(8), 651-662. DOI: 10.1007/s00226-005-0030-0

Article submitted: August 20, 2020; Peer review completed: September 20, 2020; Revised version received and accepted: March 8, 2021; Accepted: March 9, 2021; Published: April $15,2021$.

DOI: 10.15376/biores.16.2.3934-3941 